\title{
Avian electrocution mortality in relation to pole design and adjacent habitat in Spain
}

\author{
GUYONNE F. E. JANSS and MIGUEL FERRER
}

\begin{abstract}
Summary
Quantitative differences were assessed in avian mortality by electrocution between the most frequent pole designs and habitat types in south-west Spain. Pin-type insulators in natural habitats accounted for $36.9 \%$ of total avian mortality. Including all species, we estimated a mean annual death rate of 4.5 birds per 100 poles ( $95 \%$ confidence interval: 3.0-6.03), of which $53.8 \%$ were diurnal birds of prey. We identified all power poles in the distribution area of the Spanish Imperial Eagle Aquila adalberti population of the Doñana area. The estimated total mortality for adults was 0.38 birds per year and for immature eagles 3.38 , which was $1.3 \%$ of the adult population and $30.0 \%$ of the mean annual number of fledged young. Adequate modification of $18.6 \%$ of power poles in the distribution area of the eagle population could reduce the total estimated mortality by $51.6 \%$.
\end{abstract}

\section{Introduction}

Bird mortality from electrocution at overhead power lines has been identified as a conservation problem for some bird species, especially raptors (e.g. Olendorff et al. 1981, Ferrer et al. 1991). A study of Spanish Imperial Eagle Aquila adalberti, one of the most endangered raptors with a world population of some 120 breeding pairs restricted to the south-west Iberian peninsula, showed the severe impact of electrocution mortality on radio-tagged, immature birds. By burying a power line $(13 \mathrm{kV})$ in the Doñana National Park, survival of immature eagles in the first six months of their life increased from $17.6 \%$ to $80 \%$ (Ferrer and Hiraldo 1991). Of all radio-tagged Spanish Imperial Eagles, $42.1 \%$ died due to electrocution (Ferrer 1993b).

In general, poles with conductors situated over crossarms result in high mortality (Haas 1980, Olendorff et al. 1981, Ferrer et al. 1991, APLIC 1996), while habitat characteristics (e.g. soil, vegetation type, and prey density) also affect mortality rate (Benson 1981, Kochert 1980, Ferrer et al. 1991). The identification of these factors has been especially useful for designing new, safe, pole designs to prevent electrocution, as well as for developing adequate legislation in several regions of Spain to guarantee a reduction in mortality rates (Negro and Ferrer 1995). Solutions for existing pole designs have also been tested (Janss and Ferrer 1999).

Studies of the electrocution problem have mainly used data collected in single surveys, ringing recovery data and questionnaires (e.g. Fiedler and Wissner 1980, Olendorff et al. 1981, Negro 1987, Bevanger and Overskaug 1998) over relatively short periods, or using a small sample of power poles or pylons (e.g. Ferrer et al. 
1991, Onrubia et al. 1997), precluding the statistical treatment of data. Methodological studies allowing estimates of annual death rates or of statistical differences are still rare (Hobbs and Ledger 1986; Bevanger 1994). A mortality rate per pole together with habitat type, rather than an average overall mortality rate, would allow a more precise estimate of total mortality in a given area, and provide a management tool to optimize investment for bird conservation. We therefore aimed to investigate how pole design and habitat type influenced the electrocution rate of birds, by quantifying differences between different pole-habitat combinations.

\section{Study area and methods}

\section{Study area}

Our study area comprised the south-west provinces of Spain (Huelva, Sevilla and Cádiz), centred in the Doñana area, where a breeding population of Spanish Imperial Eagles exists (10-15 pairs between 1990 and 1994, Ferrer 1993b). Also included in the study were dispersion areas beyond the Doñana boundary used by immature birds of this population (Ferrer 1993a,b). The dispersion areas, which are good hunting grounds for birds of prey, extend up to $150 \mathrm{~km}$ from the Doñana natal area and are used by at least $84 \%$ of the immature eagles, but not adult eagles (Ferrer 1993a; Ferrer and Harte 1997).

Study pylons of the Doñana area were located mainly in unprotected areas adjacent to the Doñana National Park and Natural Park. Apart from the eagle population many other raptors breed in the Doñana area, while the fertile Guadalquivir delta, where Doñana is located, is one of the most important wintering areas in Europe for migrating birds. The area is also an important agricultural area (rice, cotton, horticulture), which has led to considerable human influence and electrification of the area with the potential for causing significant mortality in both breeding and wintering bird populations.

\section{Habitat and pole types}

Pylons of the Doñana area were mainly located in marshes, pine Pinus pinnea plantations and Mediterranean scrub and forest of Pistacia lentisicus and Quercus suber. Study pylons in the dispersion areas were located in small natural areas with Mediterranean scrub of Pistacia lentiscus, and cultivated areas with and without scattered oak Quercus trees. Five habitat categories were identified: (1) natural areas with trees (oak forest and dehesa, pine plantations); (2) natural areas without trees (marshland, Mediterranean scrubland); (3) extensive crops (meadows, cereal cultivation); (4) eucalyptus plantations; and (5) intensive crops (horticulture) and human-influenced areas. The presence or absence of trees may be important since Benson (1981) indicated that the absence of trees in an area may increase pole use, and thus likelihood of electrocution.

Differences in mortality rates through electrocution were expected between wooden, concrete and metal power poles, because of the differences in the conductivity of materials which contribute to a bird making a short-circuit (Negro and Ferrer 1995). However, wooden poles and concrete poles were excluded 
from further analysis due to the small numbers of each $(5.1 \%$ and $1.2 \%$ of all poles respectively). Thus, all remaining poles were made of steel with a simple circuit formed by three conductors at $13-20 \mathrm{kV}$. We further identified pole types by their insulators, where: (1) they were all suspended; (2) they were strained or anchored with jumper wires under the crossarms; or (3) a conductor passed over the crossarm (pin-type insulators, exposed jumper wires, circuit-breakers). Poles were also identified by their crossarm configurations, where: (1) there were several crossarm braces on different levels; or (2) there was only one crossarm present, i.e. all conductors were on the same level. Finally five designs were compared: one design where all poles had suspended insulators (no sufficient level of mortality was recorded when separated by crossarm configuration), two designs with strained and two with pin-type insulators in the two different crossarm configurations (Figure 1).

\section{Mortality surveys}

Three periods of fieldwork were carried out during the four-year study (19901994). During the first field period (1990-1991), 5,053 power poles were surveyed once for bird corpses of any species. Poles throughout the total distribution area of Spanish Imperial Eagle (natal and dispersion areas of immature birds) were surveyed, as well as adjacent areas normally beyond the species' range, to assess mortality in other species. The data collected in this period were used to assess differences in mortality rate between different pole-habitat combinations. In the second field period (November 1991-September 1992) a survey was conducted at two-month intervals on a selection of 1,056 poles, which represented all polehabitat combinations (six surveys in one year). These surveys began two months after the surveys of the first field period. The data of the second field period were used to estimate annual mortality per 100 poles. In the third field period (May 1993-October 1994) 18 surveys (one per month) were carried out on 179 poles. These poles were selected for their elevated rates of bird mortality in order to increase sample size. Data from these surveys were used, together with those of the second field period, to calculate the relative mortality (i.e. as a percentage) in each pole-habitat combination, yet were excluded when the annual death rate was estimated.

During each survey, the area within a $20 \mathrm{~m}$ radius from the base of each pole was searched for casualties. Most of the birds had burns on the primaries, talons or beak. All corpses were removed from the area to prevent double counts in subsequent surveys.

\section{Data analysis}

We used log-linear analysis of a two-way frequency table to evaluate differences between pole designs and habitat types (procedure CATMOD in SAS; SAS Institute 1990). The response variable was the presence or absence of dead birds by each pole (without considering total number). This analysis requires that all combinations of pole designs and habitat type existed and that all combinations had at least one positive event (a record of a dead bird). In 5.3\% of the power poles a dead bird was located. This limited the potential combinations of pole 
a.
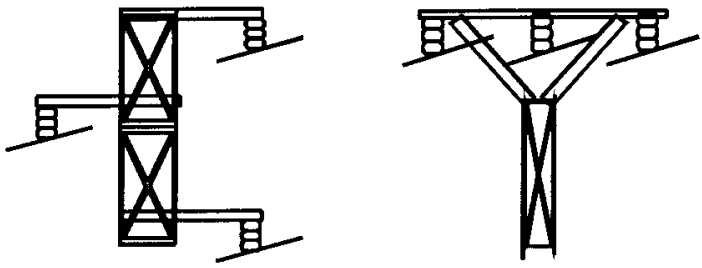

b.
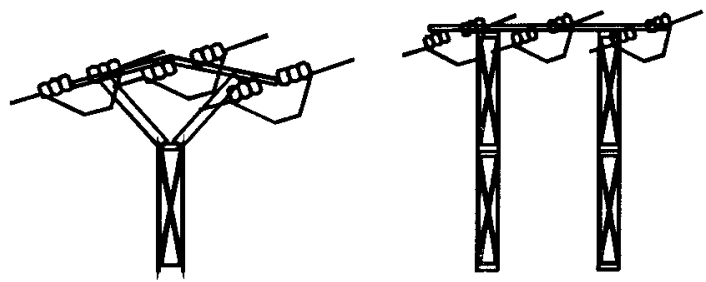

C.
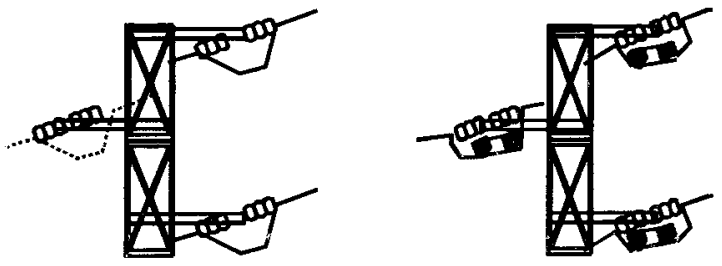

d.
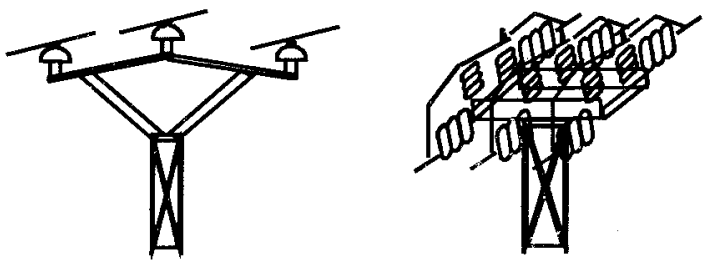

e.
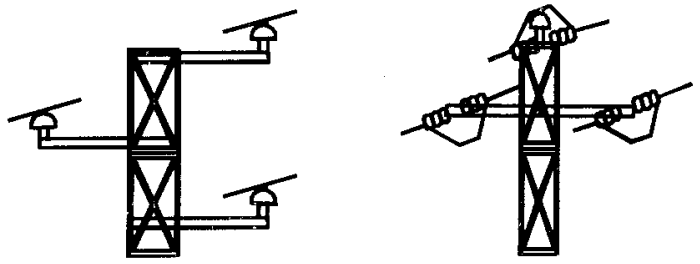

Figure 1. Crossarm configurations of power poles in the Doñana area of south-west Spain: (a) poles with suspended insulators; $(b, c)$ poles with strained insulators; $(d, e)$ poles with pin-type insulators.

designs and habitat types that could be compared. Differences between categories were contrasted post hoc by planned comparisons (SAS Institute 1990).

\section{Annual death rate: all species}

Based on the surveys of the second field period (November 1991-September 1992), we calculated the mean number of dead birds per 100 power poles. No 
mortality was recorded in some pole-habitat combinations, probably indicating a lower mortality than one bird per year rather than an absence of mortality because each pole design and habitat type separately had a level of mortality associated with it. From this (using data of the second and third field period) we calculated a relative mortality rate (percentage of dead birds) per pole design and per habitat type separately, which was possible because mortality per pole and habitat type showed no significant interaction (see Results). Then relative mortality in each pole and habitat type was averaged for the two field periods and combined in an expected distribution of dead birds per pole-habitat combination expressed in percentages. Mean average mortality could then be used to estimate mortality rate for each of the combinations.

\section{Annual death rate: Spanish Imperial Eagle}

Of all poles in the distribution area of the adult imperial eagle, those within a radius of $3.2 \mathrm{~km}$ of the nest site were assumed to pose a potential hazard to the adult population, while those poles within $6.5 \mathrm{~km}$ of the nest site and in a 3.0 $\mathrm{km}$ radius of the centre of the dispersal areas (Ferrer 1993b) were assumed hazardous to immature eagles. Observed annual mortality of the eagles was used to estimate mortality for each pole-habitat combination. Total mortality was then estimated for both age classes (adult and young) by multiplying the estimated mortality with the total number of poles in each pole-habitat combination present in the distribution area of the species.

\section{Results}

Six hundred individuals of 26 bird species, belonging to eight different taxonomic orders, were found electrocuted (Table 1). Over $80 \%$ were falconiformes and corvids. The most common casualties were Common Buzzard Buteo buteo (7.7\%), Common Raven Corvus corax (16.0\%) and Jackdaw Corvus monedula (10.2\%). Nearly 10\% of the casualties were ciconiiformes, mainly White Stork Ciconia ciconia and Cattle Egret Bubulcus ibis. One mammal, a Common Genet Genetta genetta was also recorded.

\section{Pole-habitat combinations}

During the first field period 5,053 poles were surveyed, and finally 4,088 poles were included in the log-linear analysis. Both pole design $\left(\chi^{2}=68.77,4 d f, P\right.$ $<$ o.001) and habitat type $\left(\chi^{2}=29.79,3 d f, P<0.001\right)$ were significant factors in the model contributing to bird mortality. No significant interaction between these factors was demonstrated $\left(\chi^{2}=11.05,12 d f, P=0.524\right)$. We compared the two crossarm configurations of strained insulators, but no difference in mortality was demonstrated $\left(\chi^{2}=0.84,1 d f, P=0.359\right)$, nor between the crossarm configurations of pin-type insulators $\left(\chi^{2}=3.12,1 d f, P=0.077\right)$. Mortality associated with suspended insulators was significantly less than mortality from strained insulators $\left(\chi^{2}=10.43,1 d f, P=0.001\right)$, and strained less than mortality from pin-type $\left(\chi^{2}=9.82,1 d f, P=0.002\right)$. Between both natural habitats (with trees versus without trees) no significant difference was demonstrated $\left(\chi^{2}=1.74,1 d f, P=0.187\right)$. Both natural habitats were signific- 
Table 1. Numbers of electrocution casualties per species recorded during three field surveys: $1,1990-$ 1991; 2, 1991-1992; 3, 1993-1994. Numbers of poles sampled in each survey period were 5,053, 996 and 179 , respectively

\begin{tabular}{|c|c|c|c|c|}
\hline \multirow[t]{2}{*}{ Order } & \multirow[t]{2}{*}{ Species } & \multicolumn{3}{|c|}{ Surveys } \\
\hline & & 1 & 2 & 3 \\
\hline \multirow[t]{3}{*}{ Ciconiiformes } & Ardea cinerea & 1 & & 1 \\
\hline & Bubulcus ibis & 19 & & \\
\hline & Ciconia ciconia & 27 & 6 & 1 \\
\hline \multirow[t]{13}{*}{ Falconiformes } & Aegypius monachus & 1 & & \\
\hline & Accipiter gentilis & 3 & & \\
\hline & Aquila adalberti & 3 & 1 & \\
\hline & Buteo buteo & 144 & 11 & 11 \\
\hline & Circaetus gallicus & 9 & & 2 \\
\hline & Falco peregrinus & 2 & 2 & \\
\hline & Falco tinnunculus & 10 & 2 & 2 \\
\hline & Falco spp. & 4 & & \\
\hline & Gyps fulvus & 4 & & \\
\hline & Hieraaetus fasciatus & 17 & & 1 \\
\hline & Milvus migrans & 38 & 3 & 2 \\
\hline & Milvus milvus & 34 & & \\
\hline & Milvus spp. & 16 & 1 & \\
\hline Charidriformes & Larus fuscus & 1 & & \\
\hline Columbiformes & Columba palumbus & 3 & & \\
\hline Cuculiformes & Cuculus canorus & 1 & & \\
\hline \multirow[t]{4}{*}{ Strigiformes } & Athene noctua & 2 & & \\
\hline & Bubo bubo & 5 & 1 & \\
\hline & Strix aluco & 12 & 3 & 3 \\
\hline & Tyto alba & 8 & & 3 \\
\hline \multirow[t]{2}{*}{ Piciformes } & Dendrocopos major & 1 & & \\
\hline & Picus viridis & 1 & & \\
\hline \multirow[t]{6}{*}{ Passeriformes } & Corous corax & 88 & 7 & 1 \\
\hline & Corous monedula & 60 & 1 & \\
\hline & Cyanopica cyanus & & 1 & \\
\hline & Sturnus unicolor & & & 1 \\
\hline & Unidentified birds & 11 & 6 & 2 \\
\hline & Total & 525 & 45 & 30 \\
\hline
\end{tabular}

antly different from cultivated areas $\left(\chi^{2}=14.44,1 d f, P<0.001\right)$ and eucalyptus plantations $\left(\chi^{2}=16.37,1 d f, P<0.001\right)$, but cultivated areas did not differ from eucalyptus plantations $\left(\chi^{2}=0.02,1 d f, P=0.877\right)$. From these results nine pole-habitat combinations were further analysed: poles with (1) suspended, (2) strained and (3) pin-type insulators combined with (1) natural, (2) cultivated areas/eucalyptus plantations and (3) human-influenced areas. The last habitat was not included in the analysis because of a lack of casualties.

Annual mortality rate: all species

During the second field period 45 birds were recorded belonging to 12 species (Table 1). This meant a mean annual mortality of 4.52 birds per 100 poles (95\% confidence interval: 3.00-6.03). During the third field period another 30 
Table 2. Total number (and percentage) of dead birds found by power poles and the total number of power poles in each of the second two field periods (see Table 1 for field periods). Data were averaged to calculate the estimated distribution of dead birds per pole-habitat combination

\begin{tabular}{llllllll}
\hline Field period & \multicolumn{3}{c}{ Habitat types } & & \multicolumn{3}{c}{ Pole types (insulators) } \\
\cline { 2 - 3 } & $\begin{array}{l}\text { Natural } \\
(\%)\end{array}$ & $\begin{array}{l}\text { Cultivated } \\
(\%)\end{array}$ & $\begin{array}{l}\text { Human } \\
(\%)\end{array}$ & & $\begin{array}{l}\text { Suspended } \\
(\%)\end{array}$ & $\begin{array}{l}\text { Strained } \\
(\%)\end{array}$ & $\begin{array}{l}\text { Pin-type } \\
(\%)\end{array}$ \\
\hline 2 & $23 / 464$ & $22 / 314$ & $3 / 218$ & & $7 / 483$ & $7 / 190$ & $31 / 323$ \\
& $(40.0)$ & $(48.8)$ & $(11.2)$ & & $(9.5)$ & $(25.2)$ & $(65.3)$ \\
3 & $23 / 60$ & $6 / 67$ & $2 / 52$ & & $1 / 63$ & $5 / 31$ & $24 / 85$ \\
& $(74.7)$ & $(17.4)$ & $(7.8)$ & & $(3.5)$ & $(35.1)$ & $(61.4)$ \\
\hline
\end{tabular}

dead birds were recorded. During both field periods, over $60 \%$ of the casualties were collected around poles with pin-type insulators (Table 2). About $10 \%$ of dead birds were collected in human influenced areas, while the distribution of dead birds in the other two habitat types differed between periods (Table 2).

We estimated relative mortality by averaging totals for each habitat and pole type independently and then combining those by habitat and insulator type (Table 3). Using annual mortality recorded in the second field period, the minimum mortality estimated within the study area was between 0.16 and 0.33 birds per 100 poles with suspended insulators in human-influenced areas, and the maximum was between 9.98 and 20.03 birds per 100 poles with pin-type insulators in natural areas.

\section{The case of Spanish Imperial Eagle}

Observed mortality was one Spanish Imperial Eagle per year (Table 1). Mortality per pole-habitat combination of the Spanish Imperial Eagle was estimated by assuming that mortality distribution per pole design and habitat type did not differ from the distribution obtained for all species (Table 3). Then eagle mortality was predicted to lie between 0.01 eagles per 100 poles with suspended insulators in a human-influenced area and 0.33 eagles per 100 poles with pin-type insulators in a natural area (no confidence interval could be calculated). Within the range of the total eagle population of the Doñana area, 3,953 power poles were located. When multiplying estimated mortality with total number of poles in each pole-habitat combination present, a total mortality of 0.38 adult eagles and 3.38 immature eagles per year was calculated. Pin-type poles in the natural habitat were estimated to cause $26.3 \%$ of this mortality, comprising $6.7 \%$ of total power poles. Modification with adequate mitigation measures of all poles with

Table 3. Estimated distribution of dead birds per habitat and pole type (in percentages)

\begin{tabular}{lccl}
\hline Pole type (insulators) & \multicolumn{3}{c}{ Habitat types } \\
\cline { 2 - 4 } & Natural & Cultivated & Human \\
\hline Suspended & 3.7 & 2.2 & 0.6 \\
Strained & 17.3 & 10.0 & 2.9 \\
Pin-type & 36.9 & 21.0 & 6.0 \\
\hline
\end{tabular}


strained and pin-type insulators in natural areas and cultivated areas was expected to cause a $79.7 \%$ reduction in mortality, comprising $37.2 \%$ poles registered in the area.

\section{Discussion}

Annual death rate

The estimated mean mortality of birds killed by power poles in this study should be considered a minimum estimate, because we did not correct for biases. Using Rabbit Oryctolagus cuniculus carcasses to estimate removal of casualties in the Doñana area, Ferrer et al. (1991) estimated that scavengers consumed $63 \%$ of dead birds when surveys were carried out monthly and $78 \%$ when carried out every two months. According to these estimates, recorded mortality should be multiplied by 2.7 or 4.5 respectively, to obtain a corrected estimated mortality. Due to their larger size, however, we assume that the rate of removal of eagles (about $3 \mathrm{~kg}$ ) by scavengers is considerably less than that for rabbits $(0.85 \mathrm{~kg}$; Ferrer et al. 1991, Bevanger et al. 1994).

Our sample size did not allow us to calculate differences in mortality rate based on Spanish Imperial Eagle records solely. We therefore assumed that eagle fatalities were distributed in the same way as that observed for all species. However, this distribution probably differs between species, both for habitat and pole types. Different species and age classes exhibit different habitat requirements, so an equal distribution of dead birds is not to be expected from different species between habitat types. Furthermore, the likelihood of bridging the gap between a conductor and the (earthed) crossarm braces increases with the size of the bird (Negro and Ferrer 1995) and perching behaviour differs between bird size classes (Regidor et al. 1988, Janss and Ferrer 1999). Hence, different species are not likely to be affected equally by different insulator types.

The estimated mortality for adult eagles was 0.39 birds per year and for immature eagles 3.39 , which equate to $1.32 \%$ of the adult population and $30.0 \%$ of mean annual productivity respectively (Ferrer and Calderon 1990). These figures are similar to previous estimates of 2.7 immatures and 0.29 adults to die from electrocution per year (Ferrer and Hiraldo 1991). This suggests that the assumptions we made when calculating mortality were acceptable. The importance of these mortalities must be considered in light of the population dynamics. Preadult survival is estimated to be 0.1614 (Ferrer and Calderon 1990), while survival of adult eagles is estimated 0.9393, due to which an apparently small electrocution rate of adult eagles has more severe consequences for the population than the death of a young individual (Ferrer and Hiraldo 1991).

Differences between mortality of immature and adult individuals in the Golden Eagle Aquila chrysaetos were attributed to inexperience in flying and more frequent pole use by immatures (Benson 1981; Olendorff et al. 1981). We observed that in the areas used by immature birds, $7 \cdot 3$ times more poles were present, which should be taken into account when comparing mortalities between age classes. Prime territories (i.e. with low turnover) are unlikely to be situated near dangerous power lines. 


\section{Carcass accumulation}

The quantitative differences observed have enabled the identification of general pole-habitat combinations which were responsible for the majority of mortality, as well as the estimation of total mortality in a certain area. These results have an obvious advantage for investment of conservation funds, but can also be used to evaluate the potential electrocution problem in an area. The adequate modification of all strained and pin-type insulators in natural and cultivated areas is most cost-effective, while further modification of other pole-habitat combinations is less favourable.

Our data indicate that a large sample is needed to study further the accumulation of dead birds near certain power poles, particularly as such a study should probably assess mortality in individual species and even age classes, which have different perch use (Benson 1981). A reasonable alternative to studying casualty accumulation could be the study of pole use in different habitat structures, which should be directly related to mortality rate. The importance of further study lies in the earlier mentioned optimization of the efforts applied in bird conservation. It should be stressed that due to scavenger activity pylons that cause high mortality could remain unnoticed by mortality surveys, therefore the identification of such pylons is better based on habitat and pylon characteristics.

\section{Acknowledgements}

Asistencias Técnicas Clave, s.l. coordinated the fieldwork. We thank E. Migens, J. Cepeda, and J. Sánchez for helping in the field. E. Revilla helped in the performance of log-linear analysis with SAS and I. Henderson made useful corrections to an earlier draft of the manuscript. We thank the Department of Environment of the federal government of Andalusia (AMA) and the Spanish Ministry for Environment for their collaboration. The study was financed by three Spanish utility companies: Sevillana de Electricidad, IBERDROLA and Red Eléctrica de España, by the Consejo Superior de Investigaciones Científicas, and by the federal government of Andalusia (LIFE funds of the European Community).

\section{References}

Avian Power Line Interaction Committee (APLIC). (1996) Suggested practices for raptor protection on power lines: the state of the art in 1996. Washington, D.C.: Edison Electric Institute.

Benson, P. C. (1981) Large raptor electrocution and power pole utilization: a study in six western states. Ph.D. dissertation. Provo, UT: Brigham Young University.

Bevanger, K. (1994) Bird interactions with utility structures: collision and electrocution, causes and mitigating measures. Ibis 136: 412-425.

Bevanger, K. and Overskaug, K. (1998) Utility structures as a mortality factor for raptors and owls in Norway. Pp. 381-392 in R. D. Chancellor, B. U. Meyburg, and J. J. Ferrero, eds. Proceedings of the International conference on Holartic birds of prey, Badajoz, 1995. ADENEX-WWGBP.

Bevanger, K., Bakke, F. L. and Engen, S. (1994) Corpse removal experiments with the Willow Ptarmigan (Lagopus lagopus) in power-line corridors. Kol. Gel. 16: 597-607. 
Ferrer, M. (1993a) Ontogeny of dispersal distances in young Spanish Imperial eagles. Behav. Ecol. Sociobiol. 32: 259-263.

Ferrer, M. (1993b) El guila imperial. Eurofauna 1. Madrid: Quercus.

Ferrer, M. and Calderon. J. (1990) The Spanish Imperial Eagle Aquila adalberti C.L. Brehm, 1861 in Doñana National Park (south-west Spain): a study of population dynamics, Biol. Conserv., 51: 151-161.

Ferrer, M. and Harte, M. (1997) Habitat selection by immature Spanish Imperial Eagles during the dispersal period. J. Appl. Ecol. 34: 1359-1364.

Ferrer, M. and Hiraldo, F. (1991) Management of the Spanish Imperial Eagle. Wildl. Soc. Bull. 19: 436-442.

Ferrer, M., De La Riva, M. and Castroviejo, J. (1991) Electrocution of raptors on power lines in southern Spain. J. Field Ornithol. 62(2): 54-69.

Fiedler, G. and Wissner, A. (1980) Freileitungen als tödliche Gefahr für Weisstörche (Ciconia ciconia). Ökol. Vögel. 2: 59-109.

Haas, D. (1980) Gefährdung unserer Grossvögel durch Stromschlag: eine Dokumentation. Ökol. Vögel. 2: 7-57.

Hobbs, J. C. and Ledger, J. A. (1986) Powerlines, birdlife and the golden mean. Fauna $\mathcal{E}$ Flora 44: 23-27.

Janss, G. F. E. and Ferrer, M. (1999) Mitigation of raptor electrocution on steel power poles. Wildl. Soc. Bull. 27: 263-273.

Kochert, M. N. (1980) Golden Eagle reproduction and population changes in relation to jackrabbit cycles: implications for eagle electrocutions. Pp. 71-86 in R. P. Howard, and J. F. Gore, eds. Proceedings of the workshop on raptors and energy developments. Boise, ID: Bonneville Power Administration, U.S. Fish and WildLife Service, Idaho Power Committee.

Negro, J. J. (1987) Adaptación de los tendidos eléctricos al entorno. Monografías de Alytes 1. ADENEX, Mérida.

Negro, J. J. and Ferrer, M. (1995) Mitigating measures to reduce electrocution of birds on power lines: a comment on Bevanger's review. Ibis 137: 423-424.

Olendorff, R. R., Miller, A. D. and Lehman, R. N. (1981) Suggested practices for raptor protection on power lines: the state of the art in 1981. Utah: Raptor Research Foundation (Raptor Research Report No. 4).

Onrubia, A., Purroy, F. J. and Ubeda, A. (1997) Impacto de tendidos eléctricos en la avifauna. Estudio de la eficacia de señales de visualización en los tendidos eléctricos en Madrigal de las Altas Torres Avila. Cuadernos de campo ADECAB. El Cervunal 5: 61-79.

Regidor, S., Santos, C., Ferrer, M. and Negro, J. J. (1988) Experimento con modificaciones para postes eléctricos en el Parque Nacional de Doñana. Ecologia 2: 251-256.

SAS Institute (1990) SAS/STAT user's guide, vol. 1, version 6. Cary, NC: SAS Institute.

GUYONNE F. E. JANSS and MIGUEL FERRER

Department of Applied Biology, Estación Biológica de Doñana (C.S.I.C.), Avenida de Maria Luisa s/n, Pabellón del Perú, 41013 Sevilla, Spain. E-mail: guyonne@ebd.csic.es 